\title{
MODERN VIEWS ON OXYTOCICS IN OBSTETRICS PRACTICE
}

\author{
Mohanchandra Mandal ${ }^{1}$, Dipasri Bhattacharya², Dipanjan Bagchi'3, Subhrajyoti Chattopadhyay, Suchitra Pal ${ }^{5}$
}

${ }^{1}$ Associate Professor, Department of Anaesthesiology, North Bengal Medical College, Sushrutanagar, Darjeeling, West Bengal. 2Professor, Department of Anaesthesiology, R. G. Kar Medical College, Kolkata, West Bengal.

${ }^{3}$ Consultant Anaesthesiologist, Howrah District Hospital, Howrah, West Bengal.

${ }^{4}$ Assistant Professor, Department of Anaesthesiology, North Bengal Medical College, Sushrutanagar, Darjeeling, West Bengal. ${ }^{5}$ Nursing Sister, M. Sc. Nursing (Psychiatry), Central Hospital, SE Railway, Garden Reach, Kolkata.

\section{ABSTRACT}

\section{SUMMARY}

Majority of textbooks and literature has no unitary recommendations regarding the prudent use of different oxytocics and especially oxytocin. The use of oxytocin has been re-evaluated following current understanding of physiologic changes of oxytocin receptors during pregnancy and labour. Some aspects have reached consensus, while most of the facets still in the dark of ambiguity. Literature has been searched using MeSH keywords such as 'oxytocics,' 'oxytocin,' 'postpartum haemorrhage,' 'uterine inertia' and other relevant phrases. More than 300 articles (Reviews, editorial, guidelines from different international bodies, evidence from meta-analysis and clinical investigations and others) have been consulted. In this concise review article, mostly the agreeable views regarding oxytocics are presented in a comprehensive manner. However, some aspects of conflicts are also mentioned as well. These points remain open for debate and can be the scope of future exploration.

\section{KEYWORDS}

Caesarean Section, Oxytocics/Therapeutic Use, Oxytocin/Administration and Dosage, Oxytocin/Adverse Effects, Uterine Inertia/Prevention and Control, Postpartum Haemorrhage/Prevention and Control.

HOW TO CITE THIS ARTICLE: Mandal M, Bhattacharya D, Bagchi D, et al. Modern views on oxytocics in obstetrics practice. J. Evolution Med. Dent. Sci. 2016;5(71):5224-5228, DOI: 10.14260/jemds/2016/1183

\section{INTRODUCTION}

Globally, approximate 14 million cases of Postpartum Haemorrhage (PPH) occur in a year resulting in death of estimated 125,000 women.[1,2] Peripartum haemorrhage is the leading cause of maternal mortality. It is the most common cause of maternal morbidity and mortality worldwide, accounting for $30 \%$ of maternal deaths. ${ }^{[3-5]}$ In the developing world, the risk of maternal mortality from haemorrhage is approximately 100 times higher (1 in 1000 deliveries) than that found in resource-rich nations, such as the United Kingdom (1 in 100,000).[6] Pregnant women undergoing Caesarean Delivery (CD) are at increased risk of obstetric haemorrhage, mainly due to uterine atony. The Active Management of the Third Stage of Labour (AMTSL) consists of administration of prophylactic uterotonics, controlled cord traction and uterine massage after the delivery of the placenta. Of all the AMTSL interventions, oxytocics or uterotonics are the most effective component in preventing PPH.[7] Anaesthesiologists play an important role in the peripartum care for the mothers.

\section{What are Oxytocics or Uterotonics?}

Uterotonics are drugs that are used to stimulate the myometrium or to promote uterine contractions and thereby maintain or increase the uterine tone. An oxytocinergic or oxytocic means an agent having to do with oxytocin. ${ }^{[8]}$ Uterotonics are used to induce or augment labour to stimulate delivery of the placenta and to prevent or treat postpartum haemorrhage. $[9,10]$ Common uterotonic agents

Financial or Other, Competing Interest: None.

Submission 27-07-2016, Peer Review 20-08-2016,

Acceptance 27-08-2016, Published 03-09-2016.

Corresponding Author:

Dr. Mohanchandra Mandal,

A-5, M. O. Qtrs., N. B. Medical College,

Sushrutanagar, Darjeeling,

West Bengal, India.

E-mail: drmcmandal@gmail.com

DOI: $10.14260 /$ jemds/2016/1183 are synthetic oxytocin, synthetic oxytocin analogue carbetocin, methylergometrine, carboprost and misoprostol.

\section{THE DIFFERENT OXYTOCICS}

\section{Synthetic Oxytocin}

Oxytocin is used routinely for the prevention and treatment of uterine atony after vaginal and caesarean delivery.[2,11] Prophylactic administration of oxytocin after vaginal delivery, either as a sole agent or as a component of the AMTSL reduces the risk of PPH by at least $50 \% .{ }^{[2]}$ WHO recommends its use as 10 units intramuscular (IM)/Intravenous (IV) as first-line uterotonic for prophylaxis of PPH and intravenously for the treatment of established PPH.[7] The prophylactic IM use of 10 IU oxytocin at the time of delivery of the baby is also recommended by other international bodies like the UK National Institute for Health and Care Excellence (NICE) and the International Federation of Gynecology and Obstetrics (FIGO).[3,4,12] However, no consensus exists as to the dose of IV oxytocin after $\mathrm{CD}$, as will be discussed later.

Oxytocin acts rapidly on the uterus when given via IV route (Within a minute) or IM (Within 2 minutes). But owing to its short half-life of around 10 minutes, certain strategies have been taken to prolong the effect of uterotonic action. These include the use of longer acting oxytocin analogue such as carbetocin, combining oxytocin with the long-acting ergometrine or maintenance of the oxytocin infusion. [3]

\section{Synthetic Oxytocin Analogue-Carbetocin}

This synthetic oxytocin analogue is recommended following a CD primarily for its rapid onset ( $\sim 2$ minutes) and longer duration of action (plasma half-life is around 6-7 times longer than oxytocin). It can be administered through IV (100 mcg), IM and even intranasal routes. The requirement of additional uterotonic agents and need for uterine massage are less with this drug. It is discouraged in pre-eclampsia, renal and liver disease. $[2,9,13]$ 


\section{Methyl-Ergometrine}

It is a powerful vasoconstrictor (Alpha-adrenergic receptor mediated) and also induces sustained uterine contraction. Because of the risk of hypertension (Pulmonary and systemic), coronary artery spasm and bronchospasm, it should not be used in pre-existing cardiopulmonary diseases, pre-eclampsia and concomitantly with other vasopressors. It should be used as second-line drug when the response to oxytocin is insufficient.[13] The Royal College of Obstetricians and Gynaecologists (RCOG) guideline ${ }^{[12]}$ recommends $0.5 \mathrm{mg}$ as slow IV injection for the management of uterine atony while the WHO[7] favours $0.2 \mathrm{mg}$ IV or IM injection to be repeated as necessary every 15 mins. to a maximum of $1 \mathrm{mg}$ in a 24-hour period.[4]

\section{Carboprost}

Carboprost (5-methyl prostaglandin F-2 alpha) is administered as IM injection in $250 \mathrm{mcg}$ doses; can be repeated every 15 minutes up to 8 such doses (i.e. maximum $2 \mathrm{mg}$.[12,13] Recognised adverse effects are nausea, vomiting, diarrhoea, fever, bronchospasm and hypertension. Increases in bronchial tone can be life-threatening, especially in patients with reactive airway disease. It is used as secondline agent or last resort.[12,13] Some use this drug at a dose of 250-500 mcg directly in the myometrium, although the agent is not FDA-approved for such use. It should also be used with caution in active hepatic or cardiovascular disease.

\section{Misoprostol}

This synthetic prostaglandin E-1 analogue has shown a promising role as an abortifacient and uterotonic. The drug is quickly absorbed after sublingual, oral, vaginal and rectal use. It can play a role as a first-line agent where oxytocin is not available. It is administered at a dose of 600 mcg orally or sublingually for the prevention of PPH.[7,12,13] For the treatment of $\mathrm{PPH}$, it is used as $400-800 \mathrm{mcg}$ via oral or sublingual routes (In conscious patients for faster effects) or 800-1000 mcg rectally (Longer lasting effects).[4,12,14] Diarrhoea, shivering, pyrexia and headache are common adverse effects. Pyrexia is common when the dose exceeds 600 mcg.[7,14] Previous hypersensitivity to the drug contraindicates its use. The drug can be considered as second-line agent when methyl-ergometrine is contraindicated such as preeclampsia. However, it is unlikely that it would be effective if carboprost has failed or vice versa. Unlike carboprost, it does not appear to exacerbate bronchoconstriction.

\section{Oxytocin: Receptor and Pharmacodynamics}

Oxytocin is a nonapeptide having structural similarity with vasopressin and gets secreted from the posterior pituitary. Receptors for oxytocin are most abundant in the uterus. However, these receptors are also present elsewhere such as in the heart where activation of oxytocin receptor leads to the release of Atrial Natriuretic Peptide (ANP) and Brain Natriuretic Peptide (BNP). These natriuretic peptides produce natriuresis, diuresis and vasodilation leading to hypovolaemia and hypotension. On the other hand, oxytocin administration in higher concentration can activate vasopressin receptors owing to its structural analogy and can result in an antidiuretic and presser effect. This can explain the diverse actions and adverse events related with the (Mis) use of infusions and boluses.

\section{Pharmacological Reason for Adverse Events}

Oxytocin stimulates the release of nitric oxide in the vascular endothelium to produce vasodilation.[15] Tachycardia may be due to the direct effect on specific oxytocic receptors in the myocardium, affecting atrioventricular conduction and myocardial repolarisation, besides the reflex response to hypotension. Oxytocin produces a powerful vasoconstrictive effect in umbilical and coronary vessels and mild vasoconstriction in renal, splanchnic and skeletal muscle arteries. The combination of profound hypotension, tachycardia and coronary vasoconstriction can cause a mismatch between myocardial oxygen demand and supply leading to myocardial ischaemia. These haemodynamic effects are usually transient. However, patients with preexisting heart disease or hypovolaemia may be unable to compensate for the sudden vasodilation.[16-18]

\section{RE-EVALUATION BASED ON THE LESSONS LEARNT Changes of Oxytocin Receptor during Pregnancy}

Owing to increased oestrogen level, the uterine oxytocin receptor population increases progressively during pregnancy (about 180-fold increase) and reaches the peak at term; a significant proportion of this hike occurs just before the onset of labour.[19] In late pregnancy, before the onset of labour, oxytocin receptors increase to approximately 12 times higher than in early pregnancy. Consequently, the nonlabouring uterus at term remains more sensitive to oxytocin. A low-dose of oxytocin might have an optimum efficacy, while not inviting the deleterious effects of high dose of oxytocin.[11]

It was observed that haemorrhage due to uterine atony continued or even increased despite the use of high-dose oxytocin for labour induction. This situation occurs owing to development of time- and concentration-dependent desensitisation in oxytocin receptors, and the high-dose oxytocin rendering the uterine muscle insensitive to oxytocin ('Acute receptor desensitisation').[20] In-vitro and in-vivo studies report that prior exposure to oxytocin induces myometrial oxytocin receptor desensitisation. ${ }^{[2]}$ The receptor concentration decreased 60 -fold during oxytocin-augmented labour, whereas the decrease was 300 -fold during oxytocininduced labour.[2] The oxytocin-induced desensitisation depends upon the duration of oxytocin exposure and occurs over a clinically relevant time frame of approximate 4.2 hours.[21] This can influence the optimum oxytocin dosing for adequate uterine tone following $\mathrm{CD}$ in mothers who are already receiving oxytocin. The dose of oxytocin required is nine times higher in labouring woman than non-labouring woman.[22]

The higher doses of oxytocin are unlikely to improve uterine contractions further during $\mathrm{CD}$ in labouring mother who are already receiving oxytocin. This is the basis for opting for a low-threshold for shifting to the use of other uterotonics that utilise a different mechanism of action.

\section{Large Dose 10 IU Oxytocin has Certainly Gone to Disrepute}

Rapid IV injection of large doses of oxytocin is known to produce various adverse events such as hypotension, nausea, vomiting, dyspnoea, chest pain, headache, flushing, myocardial ischaemia, ST-T segment changes, pulmonary oedema and severe water intoxication with convulsions.[11] ECG changes and cardiovascular symptoms observed with the 
use of oxytocin during CD are generally related to the dose and mode of oxytocin administration. The USA-FDA has placed a 'black box' warning restricting oxytocin use, while the Institute for Safe Medical Practice added oxytocin as a 'high-alert medicine' in 2007.[20]

\section{Recently there is a Paradigm Shift - from Bolus to Infusion}

The reported death of mothers relating to IV administration of bolus 10 units oxytocin[17] has changed the subsequent clinical practice in the UK towards using lower doses such as 5 IU bolus.[5] However, rapid IV bolus of 5 units can also lead to hypotension and tachycardia.[18] As significant haemodynamic changes have been found even after a 2 IU bolus, an even smaller initial bolus administered slowly or an oxytocin infusion alone might be a safer option.[11,23,24] In a recent editorial, Laxton $\mathrm{C}$ and Weale $\mathrm{N}^{[5]}$ mentioned that reducing the dose of the oxytocin bolus may not be the effective step in reducing adverse effects as low boluses between 0.5 to 3 IU have been shown to produce hypotension in $20-30 \%$ of patients. Rather, reducing the speed of drug delivery may be the safest, especially so in those at high risk owing to cardiac disease or hypovolaemia. [5] A recent case series ${ }^{[25]}$ reviewed the anaesthetic management of 59 highrisk pregnant mothers with cardiac disease undergoing CD where the authors used 'ultra-low doses' (0.05-0.5 IU) of oxytocin, repeated as necessary at the time of delivery in order to avoid extreme haemodynamic disturbance and excess IV fluid administration accompanying oxytocin infusions. However, it seems to be a difficult task to balance between the lowest doses of oxytocin ensuring haemodynamic stability in cardiac patients against the risk of bleeding owing to uterine atony.[26] Unfortunately, there is no consensus on the best practice for oxytocin use for this highrisk population undergoing $\mathrm{CD}$.

\section{MODIFICATION OF OXYTOCIN ADMINISTRATION IS REQUIRED IN SPECIFIC SITUATIONS}

Elective Caesarean Delivery in Non-Labouring Mother

The minimum effective bolus dose for $90 \%$ of patients (ED90) at elective CD in non-labouring mother has recently been estimated to be as low as 0.35 IU with $100 \%$ response rate at 1.0 IU.[11,27] Butwick et al[24] compared the effects of placebo $0.5,1.0,3.0$ and $5.0 \mathrm{IU}$ boluses on uterine tone during elective $\mathrm{CD}$ under regional anaesthesia. They observed that adequate uterine tone can be achieved with small bolus doses like 0.5-3 IU of oxytocin in most elective cases with no apparent benefits from 5 IU (Rather there remains a trend towards more hypotension). Increasing the bolus above 5 IU has not been found to be advantageous.[28] One recent survey found that the administration of a $10 \mathrm{IU}$ oxytocin has ceased altogether, the majority use an initial 5 IU dose while only $5.3 \%$ of lead anaesthesiologists are now using less than $5 \mathrm{IU}$ oxytocin for prophylaxis at elective CD. In that survey, over $70 \%$ of respondents did not change the dose or method of administration of oxytocin following CD in pre-eclamptic patients in whom there is potential of exaggerated haemodynamic adverse effects.[26]

\section{Emergency Caesarean Delivery in Labouring Mother}

The ED90 for oxytocin during non-elective CD for labour arrest (With prior use of oxytocin) was reported as 2.99 IU, which suggests that a higher dose of oxytocin is needed to achieve adequate uterine tone for non-elective (Emergency) CD.

\section{Infusion Oxytocin during Caesarean Delivery}

The RCOG[12] recommends a rapid infusion of oxytocin (40 IU in $500 \mathrm{~mL}$ crystalloid, to run @ $125 \mathrm{~mL} / \mathrm{h}$ ) for patients of PPH secondary to atony until haemorrhage is controlled. Unfortunately, there is limited evidence to substantiate this practice. Thomas et al[18] compared 5 IU oxytocin bolus versus an infusion (1 $\mathrm{IU} / \mathrm{min})$ during elective $\mathrm{CD}$ and observed no differences in estimated blood loss between the groups. Recently, George et al[21] studied the effect of oxytocin infusion based on an 'up-down sequential allocation' technique in women undergoing elective $\mathrm{CD}$. The authors found that ED90 of oxytocin required preventing uterine atony and PPH after an elective CD to be $0.29 \mathrm{IU} /$ minute or approximately 15 IU of oxytocin in one litre of IV fluid administered over one-hour period. This dose of oxytocin infusion is $30 \%$ less than the infusion dose currently in use. However, almost $20 \%$ of patients required additional uterotonics.

\section{'Rule of Threes'}

Recently, an evidence-based and easy protocol for the oxytocin administration during CD ('rule of threes') has been proposed by Tsen and Balki.[29] This rule recommends the first use of $3 \mathrm{IU}$ oxytocin as IV loading dose in no faster than 15 seconds. There will be a 3-minute assessment intervals. In case of inadequate uterine tone, administer 3 IU oxytocin IV rescue dose. Thus there are 3 total doses of oxytocin, 3 IU of each (Initial load plus two rescue doses) and an IV maintenance @ 3 IU/h (30 IU in 1 litre of normal saline or lactated Ringer's solution, run @100 mL/h). If inadequate uterine tone persists, there are 3 pharmacological options (Ergonovine, carboprost and misoprostol), which act following other mechanisms. The initial dose of $3 \mathrm{IU}$ oxytocin is sufficient for effective uterine contractions for both nonlabouring and labouring mother. If we are to use lower dose of oxytocin routinely, it should be used with a prophylactic infusion. In the UK, an infusion over 4 hours is most commonly used. ${ }^{[5,30]}$ Maintenance oxytocin infusion can be continued for up to 8 hours following delivery.[31] However, the optimum duration of infusion is yet to be determined. We should avoid infusing oxytocin with hypotonic fluid owing to its propensity to produce dilutional hyponatremia.

\section{Current Standpoint Regarding use of Oxytocics}

Evidence-based facts indicate that oxytocin boluses of 10 IU are no longer tenable. It seems that 10 IU oxytocin intravenously can produce changes strongly suggestive of myocardial ischaemia. Low-dose (1-3 IU) bolus oxytocin, if administered slowly can be equally effective with lesser adverse events. Rapid bolus injections of more than 3 units should preferably be avoided, especially in mothers with compromised myocardial perfusion, preexisting hypovolaemia and significant valvular heart disease or in situations where hypotension and/or tachycardia need to be avoided. Rapid infusions of oxytocin may be preferable to bolus IV dosing. Infusions minimise the haemodynamic effects and are preferred whenever possible.[15,20,29]

The varying sensitivity of oxytocin receptors in labouring 
and non-labouring uterus, complex clinical factors influencing the tone of uterus and the purpose of its use whether prophylactic or treatment - all can compound the need and effectiveness of uterotonics for a particular patient scenario.

\section{For the Prophylaxis of Uterine Atony}

Current evidence strongly favours oxytocin as the uterotonic of first choice for prophylaxis of uterine atony during CD. An initial dose of 1-3 IU intravenously over 30's is recommended in healthy parturient who are at low risk for uterine atony. Higher doses can be given as an infusion over 3-5 mins. or as a slow bolus intravenously in combination with phenylephrine to curtail the haemodynamic adverse effects. In uncomplicated cases of CD after labour arrest (With prior exposure to oxytocin), 3 IU oxytocin should be considered. In case of inadequate response to this initial dose, the same dose (3 IU) may be repeated after 3-5 mins. followed by a continuous infusion. For simplicity, it can be remembered as 'rule of threes.' In patients with significant cardiac disease, especially with pulmonary hypertension, a slow administration of 'ultra-low dose' (0.05-0.5 IU) oxytocin repeated as necessary, can be preferred to avoid extreme haemodynamic disturbance as well as the obligatory fluid load associated with oxytocin infusions.

\section{For the Treatment of Uterine Atony and Consequent Postpartum Haemorrhage}

Oxytocin should be given initially at a dose of 3-5 IU intravenously over 30's and preferably in combination with phenylephrine (50-100 mcg as IV infusion).[2,32] The RCOG recommends an infusion of oxytocin $40 \mathrm{IU}$ in $500 \mathrm{~mL}$ crystalloid at $125 \mathrm{~mL} / \mathrm{h}$ during established PPH. A low threshold should be in action for shifting to the use of alternative uterotonics relying on different mechanism of actions (Ergometrine, prostaglandins F 2-alpha and PGE $_{1}$ ) in cases of established uterine atony. In pre-eclampsia, the best second-line agent is misoprostol. Fluid resuscitation and appropriate surgical interventions are of paramount important steps.

\section{CONCLUSION}

Despite widespread use, the optimal doses and rates of oxytocin infusion to prevent or treat uterine atony during CD have not been clearly determined. The major obstetric textbooks either avoid mentioning an oxytocin dose during CD in an objective way or provide a wide dose range of 20-40 IU or alike. A stepwise, standardised, check-list driven algorithm for oxytocin use during $\mathrm{CD}$ should be available to guide the obstetric team in a comprehensive and concrete manner. This algorithm should address the issues regarding the specific doses and mode of administration of the drugs in labouring and non-labouring mother as well as for prophylactic and therapeutic purposes.

\section{REFERENCES}

1. United States agency for international development. Active management of the third stage of labor for prevention of postpartum hemorrhage: a fact sheet for policy makers and program managers. 2010. http://www.k4health.org/toolkits/pc-mnh/activemanagement-third-stage-labor-amtsl-preventionpostpartum-hemorrhage-fact.
2. Dyer RA, Butwick AJ, Carvalho B. Oxytocin for labour and caesarean delivery: implications for the anaesthesiologist. Curr Opin Anaesthesiol 2011;24(3):255-61.

3. Weeks A. The prevention and treatment of postpartum haemorrhage: what do we know, and where do we go to next? BJOG 2015;122(2):202-10.

4. Lalonde A. International Federation of Gynecology and Obstetrics. Prevention and treatment of postpartum hemorrhage in low-resource settings. Int J Gynaecol Obstet 2012;117(2):108-18.

5. Weale N, Laxton C. Prophylactic use of oxytocin at caesarean section: where are the guidelines? Anaesthesia 2013;68(10):1006-9.

6. Haeri S, Dildy GA. Maternal mortality from hemorrhage. Semin Perinatol 2012;36(1):48-55.

7. World health organization. WHO recommendations for the prevention and treatment of postpartum haemorrhage. Geneva, Switzerland: 2012. http://apps.who.int/iris/bitstream/10665/75411/1/97 89241548502_eng.pdf.

8. Uterotonic. https://en.wikipedia.org/wiki/Uterotonic.

9. Vercauteren M, Palit $S$, Soetens $F$, et al. Anaesthesiological considerations on tocolytic and uterotonic therapy in obstetrics. Acta Anaesthesiol Scand 2009;53(6):701-9.

10. Arrowsmith S, Kendrick A, Wray S. Drugs acting on the pregnant uterus. Obstet Gynaecol Reprod Med 2010;20(8):241-7.

11. Devikarani D, Harsoor SS. Are we using right dose of oxytocin? Indian J Anaesth 2010;54(5):371-3.

12. Royal college of obstetrician and gynaecologists. Prevention and treatment of postpartum haemorrhage. Royal college of obstetrician and gynaecologists' Greentop Guideline no. 52, 2009. http://www.rcog.org.uk.

13. Dyer RA, Van Dyk D, Dresner A. The use of uterotonic drugs during caesarean section. Int J Obstet Anesth 2010;19(3):313-9.

14. Leduc D, Senikas V, Lalonde AB, et al. Active management of the third stage of labour: prevention and treatment of postpartum hemorrhage. SOGC clinical practice guideline. J Obstet Gynaecol Can 2009;31(10):980-93.

15. Racine J, McConachie I. Oxytocin use and dosage during cesarean section. In: McConachie I. eds. Chap 20. Controversies in obstetric anesthesia and analgesia. UK: Cambridge University Press 2012:238-45.

16. Svanstrom MC, Biber B, Hanes $M$, et al. Signs of myocardial ischaemia after injection of oxytocin: a randomized double-blind comparison of oxytocin and methylergometrine during caesarean section. $\mathrm{Br} \mathrm{J}$ Anaesth 2008;100(5):683-9.

17. Why mothers die 1997-1999. The fifth report on confidential enquiries into maternal deaths in the United Kingdom, London: RCOG Press 2001:134-49.

18. Thomas JS, Koh SH, Cooper GM. Haemodynamic effects of oxytocin given as IV bolus or infusion on women undergoing caesarean section. $\mathrm{Br} \mathrm{J}$ Anaesth 2007;98(1):116-9. 
19. Tsen LC. Anesthesia for cesarean delivery. Chap 26. In: Chestnut DH, Tsen LC, Polley LS, et al. eds. Chestnut's obstetric anesthesia: principles and practice. $4^{\text {th }}$ edn. Mosby Elsevier 2009:559-60.

20. Gunaydin B, Tuna AT. What do current information and evidence suggest to us for oxytocin use during caesarean section? Turk J Anaesth Reanim 2015;43(2):113-5.

21. George RB, McKeen D, Chaplin AC, et al. Up-down determination of the ED(90) of oxytocin infusions for the prevention of postpartum uterine atony in parturients undergoing cesarean delivery. Can J Anaesth 2010;57(6): 578-82.

22. Balki M, Ronayne M, Davies S, et al. Minimum oxytocin dose requirement after caesarean delivery for labour arrest. Obstet Gynecol 2006;107(1):45-50.

23. Sartain JB, Barry JJ, Howat PW, et al. Intravenous oxytocin bolus of 2 units is superior to 5 units during elective caesarean section. Br J Anaesth 2008;101(6): 822-6.

24. Butwick AJ, Coleman L, Cohen SE, et al. Minimum effective bolus dose of oxytocin during elective caesarean delivery. Br J Anaesth 2010;104(3):338-43.

25. Langesaeter E, Dragsund $M$, Rosseland LA. Regional anaesthesia for caesarean section in women with cardiac disease: a prospective study. Acta Anaesthesiol Scand 2010;54(1):46-54.
26. West R, West S, Simons R, et al. Impact of dose finding studies on administration of oxytocin during caesarean section in the UK. Anaesthesia 2013;68(10):1021-5.

27. Carvalho JC, Balki M, Kingdom J, et al. Oxytocin requirements at elective cesarean delivery: a dosefinding study. Obstet Gynecol 2004;104(5 Pt 1):1005-10.

28. Sarna MC, Soni AK, Gomez M, et al. Intravenous oxytocin in patient undergoing elective cesarean section. Anesth Analg 1997;84(4):753-6.

29. Tsen LC, Balki M. Oxytocin protocols during cesarean delivery: time to acknowledge the risk/benefit ratio? Int J Obstet Anesth 2010;19(3):243-5.

30. Centre for maternal and child enquiries (CMACE). Saving mothers' lives: reviewing maternal deaths to make motherhood safer: 2006-08. The eighth report of the confidential enquiries into maternal deaths in the United Kingdom. BJOG 2011;118(Suppl 1):1-203.

31. King KJ, Douglas MJ, Unger W, et al. Five unit bolus oxytocin at cesarean delivery in women at risk of atony: a randomized, double-blind, controlled trial. Anesth Analg 2010;111(6):1460-6.

32. Farina Z, Fawcus S. Oxytocin-ensuring appropriate use and balancing efficacy with safety. S Afr Med J 2015;105(4):271-4. 